HELPINGCHILDRENAFTER VIOLENCEAND DISASTER

C hildren who have witnessed or been subjected to physical or emotional violence are vulnerable to serious problems from posttraumatic stress disorder (PTSD). It is therefore of real importance to know about the impact of violence and disa sters on children and to learn how to take steps to minimise the risk of long-term emotional harm. Children in South Africa are, unfortunately, no strangers to violence and catastrophe.

Reactions to trauma may appear immediately after the event or days or even weeks later. Loss of trust in adults and fear of the event recurring are responses seen in many children and adolescents who have been exposed to traumatic events. Crying, whimpering and excessive clinging are some of the reactions shown by young children, as is regressive behaviour such as bedwetting, fear of the dark and thumb-sucking.

Children 6 - 11 years old may show extreme withdrawal, disruptive behaviour and/ or lack of concentration. They may also be prone to nightmares, sleep problems, irrational fears, irritability, outbursts of anger and fighting. Some children may complain of stomach aches or other symptoms with no medical basis to avoid going to school.

Art and play therapy is recommended for children in primary school. Cultural differences also need to be considered because some cultures discourage expression of negative emotions. In some cases, antidepressant medication to reduce anxiety may be necessary in addition to psychotherapy.

Adolescents from 12 to 17 years react in a way similar to adults. They may have fla shbacks, nightmares, emotional numbing, avoidance of any reminders of the traumatic event, depression, substance abuse, problems $w$ ith peers and anti-social behaviour. $W$ ithdrawal and isolation, sleep disturbances, suicidal thoughts, academic decline and confusion are also common. There may be feelings of extreme guilt over this or failure to prevent injury or loss of life.

After a traumatic event, the family is usua lly the first-line resource for helping. Parents and other caring adults should:

- explain the episode of violence as well as they a re able

- encourage the children to express their feelings and listen withoutpassing judgement and help younger children to use words that express their feelings. However, do not force discussion of the traumatic event

- let the children know that it is nomal to feel upset after something bad happens

- allow time for youngsters to experience and talk about their feelings. Allow them to cry or be sad-don't expect them to be brave or tough

- reassure them that they love them and will take care of them. Stay together as a family as much as possible. Adults will also need time to come to terms with the event before they can reassure their children.

By encouraging children to develop coping- and problem-solving skills, they can leam how to mana ge anxiety and feel in control. M ost children and adolescents will, with the right support, recover almost completely from the fear and anxiety caused by a traumatic experience within a few weeks, but some will need more time to heal.

The SA Depression and Anxiety Support Group offers information, telephonic counselling and referrals to professionals. The group may be contacted by telephone on (011) 783-1374 Monday to Friday from $08 \mathrm{~h} 00$ to $19 \mathrm{~h} 00$ and on Saturday from $08 \mathrm{~h} 00$ to $17 \mathrm{~h} 00$, or visit the SADAG web site: www .anxiety.org.za.
THE SOUTH AFRICAN DEPRESSION AND ANXIETY GROPP - FIGHTINGTHE BARRIER OF STIGMA

The media and entertainment industries overw helmingly present people with mental illnesses as dangerous, violent and unpredictable individuals. These inaccurate and unfair portrayals shape the public's perception of those who suffer from mental disorders as people to be feared and avoided. Stigma dehumanises individuals and sometimes has tragic consequences. It discourages individuals and their families from getting the help they need and many will experience discrimination, whether in the workplace, medical aid schemes or social settings.

Education of the public is vital. South A fricans need to know the real deal about depressive and anxiety disorders, their signs and symptoms, and their causes. Since people with these illnesses a re athigher risk of suicide, eliminating misunderstanding and stigma can really save lives.

According to Zane W ilson, chairman and founder of the South African Depression and Anxiety Group (SADAG), 'These disorders are real illnesses that deserve the same level of understanding and treatment as diabetes, arthritis or heart disease. In South Africa patients are doubly penalised by some medical aid schemes that allow very limited periods for patients to be on medications, or pay minimally if at all after six months.'

SADAG aims to destigmatise mental illness, and to educate patients, families and the general public concerning the nature and management of depressive and anxiety illnesses as treatable medical diseases without stigma.

Stigma in the South African workplace is particularly bad, butthrough talks and presentations to workforce groups, SADAG is trying to make corporate South Africa understand that depression and anxiety can be an extension of stress and treated very easily. SADAG has also started in-house helplines for companies who wish their employees to have an anonymous place to call to discuss their problems without members of their company or medical aid knowing the more personal aspects.

\section{Do you know:}

- That many people would rather tell employers they committed a petty crime and served time in jail, than admit to being in a psychiatric hospital?

- That stigma can result in inadequate medical aid coverage for mental health services?

- That stigma leads to fear, mistrust, and violence aga inst people living $w$ ith mental illness and their families?

- That stigma can cause families and friends to turn their backs on people with mental illness?

- That stigma can prevent people from getting access to needed mental health services?

Should you require more information regarding this article or wish to contact the group please contact Yasaar at SADAG, 7 days a week from $08 \mathrm{~h} 00$ to $19 \mathrm{h00}$, tel (011) 783-1474, fax (011) 884-7074, e-mail: anxiety@iafrica.com. 